\title{
Pengaruh Nilai Hedonis Dan Nilai Utilitarian Terhadap Behavioral Intention Dengan Word Of Mouth (WOM) Sebagai Variabel Mediasi
}

\author{
Windah Estrilia Somba ${ }^{1 *}$, Sunaryo ${ }^{2}$, Mugiono $^{2}$, \\ ${ }^{1}$ Program Magister Manajemen, Fakultas Ekonomi dan Bisnis, Universitas Brawijaya \\ ${ }^{2}$ Fakultas Ekonomi dan Bisnis, Universitas Brawijaya \\ *windae7@gmail.com
}

\begin{abstract}
The purpose of this study is to analyze the direct and indirect effect of hedonic value, utilitarian value, word of mouth, and behavioral intention of consumer in Casa Baio Paradise Resort, Sulawesi Utara. This study uses questionnaires as the research instrument with 108 respondents as the sample. Sampling technique is purposive sampling. This study uses Partial Least Square (PLS) to analyzed the data. The result shows that there are : 1) a significant direct effect of hedonic value to word of mouth; 2) utilitarian value to word of mouth; 3) utilitarian value and word of mouth to behavioral intention. This study also confirm that word of mouth full mediates the influence of hedonic value to behavioral intention and partial mediates the influence of utilitarian value to behavioral intention. The other result shows that there is no significant relationship between hedonic value and behavioral intention.
\end{abstract}

Keywords: Behavioral Intention, Hedonic Value, Utilitarian Value, Word of Mouth

https://doi.org/10.26905/jmdk.v6i1.2071

\section{LATAR BELAKANG}

Dunia bisnis yang bergerak di bidang jasa saat ini sedang mengalami perkembangan yang cukup pesat, baik itu bidang transportasi online, kecantikan, terlebih khusus bisnis yang bergerak dibidang pariwisata. World Tourism Organization (UNWTO, 2015) mencatat bahwa pariwisata telah memberikan kontribusi terhadap pendapatan dunia sebesar 9,5\%. Bahkan pariwisata mampu menciptakan 1 dari 11 lapangan pekerjaan di seluruh dunia. Banyaknya jenis usaha pariwisata, menyebabkan persaingan dalam dunia bisnis menjadi semakin kompetitif.

Perkembangan dunia wisata di berbagai negara pun semakin pesat, terutama di
Indonesia. Pariwisata menjadi sebuah prioritas nasional dalam RPJM 2015-2019. Pariwisata merupakan salah satu dari lima sektor prioritas pembangunan 2017, yaitu pangan, energi, maritim, pariwisata, kawasan industri dan Kawasan Ekonomi Khusus (KEK). Menteri Pariwisata Arief Yahya menyampaikan bahwa Pariwisata adalah kunci pembangunan, kesejahteraan dan kebahagiaan. Indonesia memiliki potensi wisata untuk dikembangkan menjadi destinasi pariwisata tingkat dunia.

Provinsi Sulawesi Utara dipilih menjadi lokasi dilakukannya penelitian ini karena provinsi ini memiliki budaya yang unik, keindahan dan kekayaan alam, dan keramahtamahan penduduk yang merupakan aset negara yang sangat potensial untuk terus 
dikembangkan dan dikelola oleh Pemerintah Daerah. Masyarakat Sulawesi Utara pada umumnya menyukai liburan ke tempattempat pariwisata yang menurut mereka nyaman. Masyarakat Sulawesi Utara juga sangat menyukai hal-hal yang tergolong baru. Ketika mereka merasa nyaman dengan hal-hal baru yang mereka dapatkan dari suatu tempat, maka akan mendorong seseorang untuk merekomendasikan barang dan jasa tersebut pada orang lain. Selain itu akan memunculkan niat para pelanggan untuk kembali mengkonsumsi barang atau jasa tersebut. Penjelasan tersebut menunjukkan bahwa salah satu hal yang perlu diperhatikan oleh pariwisata di Sulawesi Utara adalah niat berperilaku konsumen. Niat berperilaku merupakan pengalaman yang didapatkan seorang konsumen atas barang atau jasa, dan dapat membantu mereka untuk membentuk sikap berperilaku untuk berkunjung kembali dan merekomendasikan hal-hal yang positif tentang barang atau jasa tersebut (Han dan Kim, 2009.

Penelitian ini berfokus pada beberapa variabel yang berkaitan dengan nat berperilaku konsumen di tempat wisata, yaitu nilai hedonis, nilai utilitarian, dan word of mouth. Nilai hedonis dapat menjadi kebutuhan utama dalam pariwisata, karena pengunjung datang berwisata untuk mencari kesenangan lewat fasilitas dan pemandangan sekitar. Nilai utilitarian dapat dianggap penting karena nilai ini memberikan manfaat secara psikologis kepada para pengunjung dengan menjawab kebutuhan seperti kegiatan bisnis, refreshing dan hiburan bagi para pengunjung lewat fasilitas-fasilitas dan pelayanan yang ditawarkan tempat wisata (Chen dan Tsai, 2007). Word of mouth dapat mempengaruhi perilaku seorang konsumen. Word of mouth dapat menguntungkan suatu tempat wisata lewat hal-hal baik yang akan diceritakan para pengunjung kepada orang lain berdasarkan pengalaman yang mereka dapatkan dari tempat wisata tersebut (Jalilvand dan Samiei, 2011).
Beberapa penelitian telah dilakukan terkait hubungan antara nilai hedonis terhadap niat berperilaku seorang konsumen dan menunjukkan hasil yang signifikan (Luk, et. al, 2013; Nejati dan Moghaddam, 2012; Hyun, et. al, 2011; dan Park dan Sullivan, 2009). Hasil ini bertentangan dengan penelitian Ha dan Jang (2009), dan Overby dan Lee (2006) yang menemukan bahwa nilai hedonis tidak berpengaruh signifikan terhadap niat berperilaku. Beberapa penelitian juga menemukan bahwa nilai utilitarian memiliki hubungan yang signifikan dengan niat berperilaku, (Nejati dan Moghaddam, 2013; Ryu, et. al, 2010; Luk, et. al, 2013; Ha dan Jang, 2009; dan Hyun, et. al, 2011). Hasil ini bertentangan dengan penelitian Chiu, et. al (2014), dan Maio dan Olson (1995) yang menemukan bahwa nilai utilitarian tidak berpengaruh signifikan terhadap niat berperilaku.

Dengan adanya ketidaksamaan hasil dalam penelitian-penelitian ini, maka peneliti tertarik untuk lebih jauh menganalisis hubungan antara nilai hedonis dan niat berperilaku, juga nilai utilitarian dan niat berperilaku dengan menambahkan variabel mediasi yaitu word of mouth. Penggunaan word of mouth sebagai variabel mediasi pengaruh nilai hedonis dan nilai utilitarian terhadap niat berperilaku, didasarkan pada penelitian yang dilakukan oleh Ryu, et. al, (2010), yang menyinggung bahwa word of mouth dapat menjadi penghubung keterkaitan antara nilai hedonis dan nilai utilitarian terhadap niat berperilaku. Gallarza dan Saura (2006) juga dalam penelitiannya menemukan bahwa word of mouth dapat membentuk persepsi dan niat berperilaku seorang wisatawan lewat nilainilai yang mereka dapatkan ketika melakukan kegiatan wisata.

Penggunaan Casa Baio Paradise Resort lokasi sebagai objek penelitian didorong oleh latar belakang masyarakat sulut yang pada umumnya menyukai liburan ke tempat-tempat pariwisata yang menurut mereka nyaman dan layak untuk dikunjungi. Masyarakat sulawesi utara juga dikenal dengan masyarakat yang 
menyukai hal-hal yang baru. Dengan adanya water sport, diving, dan olahraga golf yang ditawarkan pihak resort, dapat menimbulkan niat masyarakat untuk datang ketempat ini dan mencoba wahana baru tersebut.

\section{Kajian Pustaka \\ Behavioral Intention}

Niat berperilaku merupakan pengalaman yang didapatkan seorang konsumen atas barang atau jasa, dan dapat membantu mereka untuk membentuk sikap berperilaku untuk berkunjung kembali dan merekomendasikan hal-hal yang positif tentang barang atau jasa tersebut pada orang lain, hal ini dapat memprediksi perilaku konsumen dimasa yang akan datang (Han dan Kim, 2009). Oliver (1997) mendefinisikan niat perilaku sebagai "the stated likelihood to engage in a particular behavior". Berdasarkan definisi ini, niat perilaku dapat digambarkan sebagai kemungkinan pelanggan untuk loyal terhadap perusahaan, dan kembali ke tempat tersebut karena pelayanannya memuaskan, dan pelanggan tersebut akan merekomendasikan hal ini kepada keluarga, teman, dan orang lain (Ryu, et. al, 2010; Han dan Kim, 2009).

\section{Nilai Hedonis}

Dilihat dari sudut pandang nilai hedonis, aktifitas konsumsi yang dilakukan oleh konsumen didasari oleh adanya keinginan untuk hal-hal yang berkaitan dengan hiburan. Seseorang akan termotivasi untuk melakukan suatu kegiatan karena mereka mengincar kesenangan dari waktu luang dan rekreasi, atau peran emosional dari suasana hati dan kenikmatan (Hirschman \& Holbrook, 1982).

Saat ini riset pemasaran mulai fokus pada nilai hedonis dari pengalaman konsumsi yang dirasakan oleh konsumen, dimana nilai hedonis itu sendiri dilihat sebagai respon yang berkaitan dengan hal afektif dan kesenangan (O'curry dan Strahilevizt, 2001). Secara alamiah, evaluasi Hedonis lebih afektif daripada kognitif.
Nilai-nilai Hedonis tidak bersifat instrumental, lebih kepada pengalaman dan hal-hal afektif dan berhubungan dengan unsur atau atribut atau jasa yang bersifat kasat mata (intangible).

\section{Nilai Utilitarian}

Produk utilitarian umumnya tidak berhubungan dengan perasaan/kondisi. Aspek utilitarian dari nilai konsumen memainkan peran yang lebih penting dalam kepuasan pelanggan dan niat berperilaku (Ryu, et. al, 2010). Dimensi utilitarian terkait dengan aspek produk atau layanan yang efisien, sesuai tugas, dan ekonomis. Perilaku konsumen yang utilitarian berorientasi pada tugas, dan konsumen ini cenderung rasional.

Pembeli yang utilitarian adalah konsumen yang selalu berpikir secara hatihati dan memikirkan tingkat efisiensi produk sebelum dibeli dan selanjutnya, utilitarian digambarkan sebgai perilaku yang berkaitan dengan fungsi sebuah produk atau jasa atau yang berkaitan dengan tugas, dan pekerjaan (Babin, et. al, 1994). Nilai utilitarian itu sendiri bisa dijelaskan sebagai kegunaan atau manfaat yang dirasakan seseorang dalam kaitannya dengan kemampuan suatu produk untuk melaksanakan fungsinya.

\section{Word of Mouth (WOM)}

Word of mouth (WOM) adalah komunikasi tentang produk dan layanan antara orang-orang yang dianggap bebas dalam memilih perusahaan yang menyediakan produk atau layanan, dan dapat dianggap sebagai perantara bebas dari perusahaan kepada orang lain (Jalilvand \& Samiei, 2011). Word of Mouth (WOM) terjadi ketika pelanggan berbicara kepada orang lain mengenai pendapatnya tentang suatu merk, produk, layanan atau perusahaan tertentu pada orang lain (Brown, et.al, 2005). Apabila pelanggan menyebarkan opininya mengenai kebaikan produk maka disebut sebagai WOM positif, sebaliknya tetapi bila pelanggan menyebarluaskan opininya mengenai keburukan produk maka disebut sebagai WOM negatif. WOM Positif dapat berarti apabila seseorang melakukan bisnis 
dengan suatu perusahaan dan melakukan rekomendasi kepada orang lain mengenai

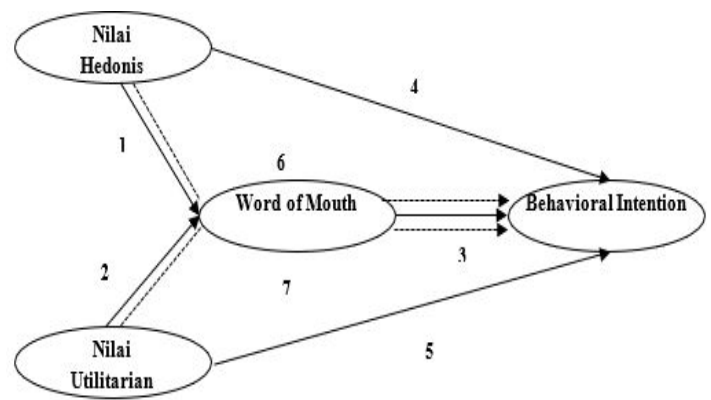

perusahaan tersebut (Brown, et al, 2005).

Gambar 1. Kerangka Konsep Penelitian

Sumber: Kajian Penelitian terdahulu (2017)

Hipotesis dalam penelitian ini, adalah:

$\mathrm{H}_{1}$ : Nilai hedonis memberikan pengaruh terhadap word-of mouth

$\mathrm{H}_{2}$ : Nilai utilitarian memberikan pengaruh terhadap word of mouth

$\mathrm{H}_{3}$ : Word of mouth memberikan pengaruh terhadap niat berperilaku

$\mathrm{H}_{4}$ : Nilai Hedonis berpengaruh terhadap niat berperilaku

$\mathrm{H}_{5}$ : Nilai Utilitarian berpengaruh terhadap niat berperilaku

$\mathrm{H}_{6}$ : Nilai Hedonis berpengaruh terhadap niat berperilaku, melalui word of mouth

$\mathrm{H}_{7}$ : Nilai Utilitarian berpengaruh terhadap niat berperilaku, melalui word of mouth

\section{Definisi Operasional Variabel \\ Nilai Hedonis}

Pengukuran nilai hedonis mengacu pada empat (4) indikator menurut Ryu et. al, 2010; To, et. al, 2007, yaitu : 1) Suasana hati yang baik, 2) Tempat yang menyenangkan, 3) View yang menakjubkan, dan 4) Pengalaman baru.

\section{Nilai Utilitarian}

Pengukuran nilai utilitarian juga mengacu pada tiga (3) indikator menurut Ryu et. al, 2010; To, et. al, 2007, yaitu : 1) Bermanfaat, 2) menghabiskan banyak biaya, 3) Pelayanan yang baik

\section{Behavioral Intention}

Pengukuran niat berperilaku mengacu pada empat (4) indikator menurut Ryu, et. al, 2010, Ladhari, 2009, yaitu : 1) Niat kembali, 2) Sering untuk berkunjung, 3) Bersedia membayar mahal, 4) Kesetiaan.

\section{Word of Mouth}

Pengukuran word of mouth dalam penelitian ini mengacu pada indikator menurut Molinari, et. al, 2008, yaitu : merekomendasikan.

\section{METODE}

Jenis penelitian ini adalah explanatory research. PopulasI dalam penelitian ini adalah seluruh masyarakat yang pernah mengunjungi Casa Baio Paradise Resort dan sampel penelitian adalah responden yang sudah pernah mengunjungi dan menikmati fasilitas dan layanan yang diberikan Casa Baio Paradise Resort, dan responden yang mengambil keputusan untuk datang di Casa Baio Paradise Resort sebanyak 108 orang. Menggunakan metode analisis PLS (Partial Least Square) dengan alat analisis smartPLS 3.0.

\section{HASIL DAN PEMBAHASAN \\ Hasil}

Hasil analisis hipotesis masing-masing jalur yang diperoleh dari hasil analisis menggunakan software smartPLS 3.0 adalah sebagai berikut:

Tabel 1. Hasil Analisis Pengaruh Langsung Antar Variabel

\begin{tabular}{|c|c|c|c|c|c|}
\hline \multirow{2}{*}{ Hipotesis } & \multirow{2}{*}{$\begin{array}{l}\text { Hubungan } \\
\text { Variabel }\end{array}$} & \multirow{2}{*}{$\begin{array}{c}\text { Path } \\
\text { Coeffi }\end{array}$} & \multicolumn{2}{|c|}{ Estimate } & \multirow{2}{*}{ Keputusan } \\
\hline & & & $t$-stat & p-values & \\
\hline$\overline{\mathrm{H} 1}$ & NH $->$ WOM & 0,24 & 2,806 & 0,005 & Diterima \\
\hline $\mathrm{H} 2$ & NU $->$ WOM & 0,492 & 5,844 & 0 & Diterima \\
\hline $\mathrm{H} 3$ & WOM -> BI & 3,215 & 2,164 & 0,031 & Diterima \\
\hline $\mathrm{H} 4$ & $\mathrm{NH}->\mathrm{BI}$ & 0,077 & 0,792 & 0,429 & Ditolak \\
\hline H5 & $\mathrm{NU}->\mathrm{BI}$ & 3,587 & 7,668 & 0 & Diterima \\
\hline
\end{tabular}

Sumber: Data primer diolah, 2017

Berdasarkan hasil pengujian hipotesis H1, H2, H3, dan, H5 memiliki nilai $t$ statistics $>1.96$ dan nilai $p$-values $<0.05$, 
maka dinyatakan signifikan, sehingga dapat disimpulkan bahwa hipotesis diterima. Pada H4, Nilai $t$-statistics $<1.96$ dan nilai $p$-values $>0.05$, maka dinyatakan tidak signifikan, sehingga dapat disimpulkan bahwa nilai hedonis tidak berpengaruh signifikan terhadap niat berperilaku. Dengan demikian, hipotesis 4 ditolak.

\section{Peran Mediasi Word Of Mouth Pada Pengaruh Nilai Hedonis Terhadap Niat Berperilaku}

Tahap pertama, melakukan estimasi direct effect tanpa memasukkan variabel mediasi.

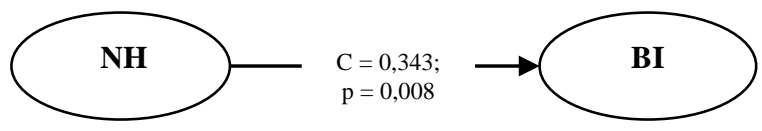

Gambar 2. Model Direct Effect

Sumber: Data primer diolah, 2017

Tahap kedua, melakukan estimasi indirect effect dengan triangle PLS SEM model (memasukkan variabel mediasi dalam model)

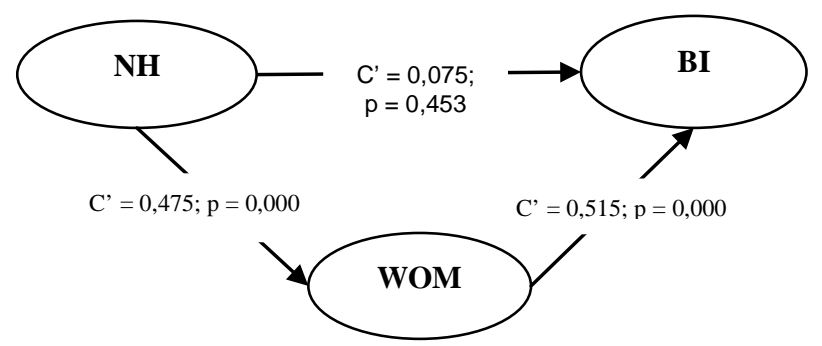

Gambar 3. Model Indirect Effect

Sumber: Data primer diolah, 2017

Berdasarkan hasil pengujian pada Gambar 2 dan 3 persyaratan uji mediasi sudah dipenuhi. Diketahui koefisien direct effect nilai hedonis terhadap niat berperilaku (c) signifikan pada langkah 1 dan koefisien jalur indirect effect nilai hedonis terhadap word of mouth (a) dan word of mouth terhadap niat berperilaku (b) juga signifikan pada langkah 2 . Koefisien pengaruh langsung nilai hedonis terhadap niat berperilaku (c) adalah sebesar 0,343, sedangkan pengaruh tidak langsung nilai hedonis terhadap niat berperilaku (c") turun menjadi 0,075 dan menjadi tidak signifikan. Maka, word of mouth dinyatakan sebagai mediasi sempurna (full mediation) pada pengaruh nilai hedonis terhadap niat berperilaku. Sehingga hipotesis 6, diterima.

\section{Peran Mediasi Word Of Mouth Pada Pengaruh Nilai Utilitarian Terhadap Niat Berperilaku}

Tahap pertama, melakukan estimasi direct effect tanpa memasukkan variabel mediasi.

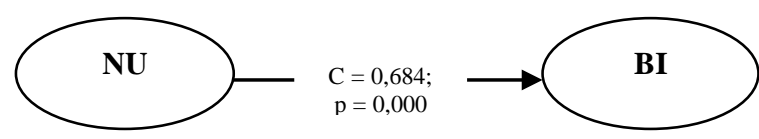

Gambar 4. Model Direct Effect

Sumber: Data primer diolah, 2017

Tahap kedua, melakukan estimasi indirect effect dengan triangle PLS SEM model (memasukkan variabel mediasi dalam model)

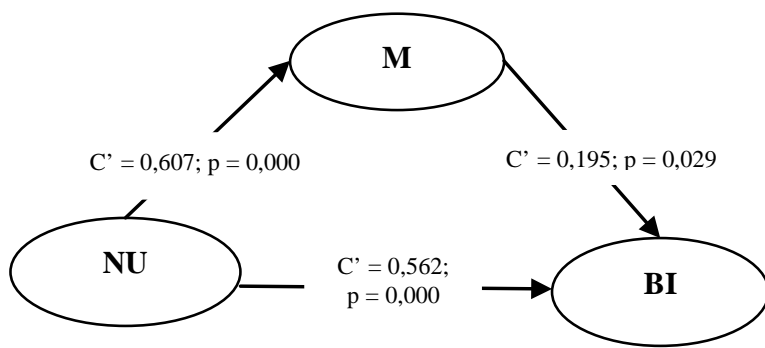

Gambar 5. Model Indirect Effect

Sumber: Data primer diolah, 2017

Berdasarkan hasil pengujian pada Gambar 4 dan 5, persyaratan uji mediasi juga sudah dipenuhi. Diketahui koefisien pengaruh langsung (direct effect) nilai utilitarian terhadap niat berperilaku (c) signifikan pada langkah 1 dan koefisien jalur pengaruh tidak langsung (indirect effect) nilai utilitarian terhadap word of mouth (a) dan word of mouth terhadap niat berperilaku (b) juga signifikan pada langkah 2. Koefisien pengaruh langsung (direct effect) nilai 
utilitarian terhadap niat berperilaku (c) adalah sebesar 0,684, sedangkan koefisien pengaruh tidak langsung (indirect effect) nilai utilitarian terhadap niat berperilaku (c") turun menjadi 0,562 WO dan tetap signifikan. Maka, word of mouth dinyatakan sebagai mediasi sebagian (partial mediation) pada pengaruh nilai utilitarian terhadap niat berperilaku. Nilai koefisien pengaruh tidak langsung (indirect effect) dihitung dengan mengalikan nilai koefisien a dengan $b$, sehingga diperoleh nilai sebesar $0,607 \mathrm{x}$ $0,195=0,118$. Sehingga hipotesis 7 , diterima.

\section{Pembahasan \\ Pengaruh Nilai Hedonis terhadap Word of Mouth}

Hasil penelitian ini menunjukkan bahwa nilai hedonis berpengaruh signifikan terhadap word of mouth. Semakin tinggi tingkat kesenangan atau kenikmatan (nilai hedonis) yang ditawarkan suatu tempat, maka semakin memberikan pengaruh yang kuat bagi seorang pelanggan untuk melakukan word of mouth mengenai tempat tersebut. Hasil penelitian ini mendukung penelitian-penelitian sebelumnya yang menjelaskan bahwa nilai hedonis memberikan pengaruh terhadap word of mouth baik itu word of mouth positif maupun word of mouth negatif (Babin, 1994; Carpenter dan Fairhust, 2005; Sen dan Lerman, 2007). Umumnya, seseorang akan menceritakan kenikmatan yang dia dapatkan dari sebuah produk pada orang lain, dan hal itu yang akan menjadi daya tarik konsumen lain terhadap produk tersebut (Jalilvand, et. al, 2011).

Objek wisata Casa Baio Paradise Resort menawarkan nilai hedonis yang sangat menarik perhatian masyarakat. Keindahan alam yang ditawarkan, fasilitasfasilitas yang berbeda dari hotel pada umumnya yang dapat menjadikan pengalaman baru bagi para pengunjung, suasana yang membuat para pelanggan betah, dapat memberikan dampak yang positif bagi para pengunjung yang datang ditempat ini. Nilai-nilai hedonis yang didapat dari empat ini akan membuat para pengunjung menceritakan hal-hal yang menurut mereka baik dan positif tentang tempat ini kepada orang lain (keluarga dan kerabat). Dengan demikian word of mouth dapat menguntungkan Casa baio Paradise Resort lewat nilai-nilai hedonis yang diterapkan ditempat tersebut.

\section{Pengaruh Nilai Utilitarian terhadap Word of Mouth}

Hasil penelitian ini menunjukkan bahwa nilai utilitarian berpengaruh signifikan terhadap word of mouth. Artinya, semakin tinggi tingkat manfaat (nilai utilitarian) yang ditawarkan suatu tempat maka akan memberikan pengaruh yang kuat pula bagi seorang pelanggan untuk melakukan word of mouth. Hasil penelitian ini mendukung penelitian-penelitian sebelumnya yang menjelaskan bahwa nilai utilitarian memberikan pengaruh terhadap word of mouth baik itu word of mouth positif maupun word of mouth negatif (Babin, 1994; Babin et, al, 2005; Carpenter dan Fairhust, 2005; Hartline dan Jones, 1996; Sen dan Lerman, 2007).

Nilai-nilai utilitarian yang diterapkan Casa Baio paradise resort adalah manfaat yang diberikan tempat tersebut, pelayanan, dan biaya yang akan dikeluarkan oleh para pelanggan sesuai atau tidak dengan kebutuhan mereka. Hasil penelitian menunjukkan bahwa pelayanan yang diberikan oleh pihak resort sudah sesuai dengan harapan para pelanggan. Begitu juga dengan biaya yang mereka keluarkan sepadan dengan pelayanan yang mereka terima. Banyak manfaat yang didapat ketika berkunjung ditempat ini. Dengan demikian, para pelanggan merasa terdorong untuk menceritakan hal-hal positif terkait nilai utilitarian yang didapatkan ketika berwisata di Casa Baio Paradise Resort.

\section{Pengaruh Word Of Mouth Terhadap Niat Berperilaku}

Hasil penelitian menunjukkan bahwa word of mouth memberikan pengaruh yang signifikan terhadap niat berperilaku seorang 
konsumen. Artinya, semakin besar word of mouth yang disampaikan maka akan semakin memberikan dampak yang signifikan terhadap niat berperilaku pelanggan. Hasil penelitian ini mendukung penelitianpenelitian sebelumnya yang menyatakan bahwa word of mouth memberikan pengaruh terhadap niat berperilaku (Chevalier dan Mayzlin, 2006; Xia dan Bechwati, 2008; Soderlund dan Rosengren, 2006).

Berdasarkan observasi yang telah dilakukan di lokasi penelitian, beberapa pengunjung mendapatkan informasi mengenai Casa Baio Paradise Resort lewat keluarga dan kerabat mereka yang sudah pernah berkunjung ditempat ini. Mereka memberikan informasi yang positif mengenai tempat ini, sehingga pengunjung merasa tertarik untuk datang berwisata. Dengan demikian word of mouth dapat dianggap sebagai perantara dari perusahaan (Casa Baio) kepada orang lain (Jalilvand dan Samiei, 2011).

\section{Pengaruh Nilai Hedonis Terhadap Niat Berperilaku}

Hasil penelitian menunjukkan bahwa nilai hedonis tidak memberikan pengaruh yang signifikan terhadap niat berperilaku. Artinya, nilai hedonis yang ditawarkan pihak resort tidak mampu menciptakan niat berperilaku seorang konsumen. Hasil penelitian ini mendukung penelitian yang menyatakan bahwa nilai hedonis tidak memberikan pengaruh yang signifikan terhadap niat berperilaku (Overby dan Lee, 2006, dan Ha dan Jang, 2009). Namun, hasil ini tidak sesuai dengan hasil yang menunjukkan bahwa nilai hedonis memberikan pengaruh yang signifikan terhadap niat berperilaku (Luk, et. al, 2013; Nejati dan Moghaddam, 2012; Hyun, et. al, 2011; Park dan Sullivan, 2009).

Casa Baio telah menerapkan nilai-nilai hedonis demi terciptanya niat berperilaku yang positif para pelanggan terhadap resort. Tapi nyatanya, nilai hedonis tersebut tidak memberikan pengaruh yang signifikan terhadap niat berperilaku pelanggan. Pemandangan yang menakjubkan, dan tempat yang menyenangkan, serta memberikan pengalaman baru tidak cukup membuat munculnya niat berperilaku pelanggan. Hal ini juga dapat dilihat pada indikator niat berperilaku yang memiliki nilai cukup, seperti sering berkunjung, kesetiaan, dan bersedia membayar mahal. Para pelanggan akan lebih sering untuk berkunjung, ketika pihak resort rutin dalam memperbarui fasilitasnya dan mempertahankan keindahan sekitar resort. Sehingga mereka tidak merasa rugi dengan biaya yang akan mereka keluarkan, dan hal baru tersebut dapat membentuk minat mereka untuk kembali ketempat ini. Pihak resort perlu untuk menambahkan hal-hal baru lagi demi memunculkan niat para pelanggan untuk kembali ke tempat ini.

\section{Pengaruh Nilai Utilitarian terhadap Niat Berperilaku}

Hasil penelitian menunjukkan bahwa nilai utilitarian memberikan pengaruh yang signifikan terhadap niat berperilaku. Artinya, nilai utilitarian yang ditawarkan pihak resort mampu menciptakan niat berperilaku seorang konsumen. Hasil penelitian ini mendukung penelitian yang menyatakan bahwa nilai utilitarian memberikan pengaruh yang signifikan terhadap niat berperilaku (Nejati dan Moghaddam, 2013; Ryu, et. al, 2010; Luk, et. al, 2013; Ha dan Jang, 2009; Hyun, et. al, 2011). Namun, hasil ini tidak sesuai dengan hasil yang menunjukkan bahwa nilai utilitarian tidak memberikan pengaruh yang signifikan terhadap niat berperilaku (Chiu, et, al, 2014; Maio dan Olson, 1994).

Casa Baio Paradise Resort selalu mengedepankan pelayanan mereka. Pihak resort dalam tujuannya adalah menempatkan pelayanan yang maksimal demi kebahagiaan dan kenyamanan para klien dan pengunjung. Pelayanan yang diberikan oleh pihak resort sudah sangat maksimal sehingga para pelanggan pun merasa puas. Begitupun para pelanggan merasakan banyak manfaat yang mereka terima ketika berwisata ditempat ini. Mereka merasa bahwa biaya yang mereka keluarkan sepadan dengan pelayanan dan 
manfaat yang mereka terima. Sehingga dapat disimpulkan bahwa nilai utilitarian dari tempat ini dapat memberikan pengaruh yang positif bagi para pelanggan, sehingga mereka memiliki niat untuk kembali berwisata ditempat ini.

\section{Pengaruh Nilai Hedonis terhadap Niat Berperilaku melalui Word of mouth}

Hasil dalam penelitian ini menunjukkan bahwa word of mouth dapat memediasi pengaruh nilai hedonis terhadap niat berperilaku. Sifat mediasi yang diberikan oleh word of mouth adalah mediasi sempurna (full mediation). Artinya, nilai hedonis dapat memberikan pengaruh terhadap niat berperilaku hanya jika melewati word of mouth. Tanpa adanya variabel word of mouth, nilai hedonis tidak akan berpengaruh terhadap niat berperilaku. Hasil penelitian ini mendukung pernyataan yang menjelaskan bahwa word of mouth dapat menjadi penghubung keterkaitan nilai hedonis dan niat berperilaku (Ryu, et. al, 2010), juga word of mouth dapat membentuk persepsi dan niat berperilaku seorang wisatawan lewat nilai-nilai yang mereka dapatkan ditempat wisata (Gallarza dan Saura, 2006).

Observasi yang dilakukan pada objek penelitian menunjukkan bahwa keindahan alam, dan pengalaman saja tidak cukup untuk memunculkan niat berperilaku seorang konsumen. Word of mouth dikatakan sebagai perantara perusahaan kepada orang lain (Jalilvand dan Samiei, 2011). Nilai hedonis yag ditawarkan Casa Baio paradise resort selalu berubah. Baru-baru ini, objek wisata casa baio baru saja menambahkan satu jenis wahana air dalam fasilitasnya. Pelanggan yang sudah lama datang berwisata tidak akan mengetahui hal tersebut. Lewat word of mouth, pelanggan yang sudah pernah berkunjung akan merasa penasaran dengan hal baru tersebut dan datang mencobanya. Pada latar belakang dijelaskan bahwa masyarakat sulawesi utara sangat menyukai hal-hal yang baru.

Hasil sebelumnya menjelaskan bahwa nilai hedonis tidak dapat memberikan pengaruh yang signifikan terhadap niat berperilaku. Hal ini dapat dsebabkan karena perusahaan tidak memperbarui fasilitasfasilitasnya, jadi pelanggan merasa bosan dan memutuskan untuk tidak kembali ketempat tersebut. Fasilitas-fasilitas baru tersebut dapat menciptakan pengalaman baru bagi para konsumen yang datang di empat ini. Word of mouth sangat diperlukan guna menambah informasi terbaru dari pihak resort kepada masyarakat sekitar. Pelaku wom dapat dianggap sebagai sumber informasi yang dapat dipercaya, dan dapat memberikan informasi yang tidak terlihat secara langsung oleh perusahaan tersebut (Zeithaml, et. al, 1996).

\section{Pengaruh Nilai Utilitarian terhadap Niat Berperilaku melalui Word of Mouth}

Hasil dalam penelitian ini menunjukkan bahwa word of mouth dapat memediasi pengaruh nilai utilitarian terhadap niat berperilaku. Sifat mediasi yang diberikan oleh word of mouth adalah mediasi sebagian (partial mediation). Artinya, word of mouth dapat menjembatani pengaruh nilai utilitarian terhadap niat berperilaku. Namun tanpa adanya word of mouth, pada dasarnya nilai utilitarian memang mampu memberikan pengaruh terhadap niat berperilaku. Hasil penelitian ini juga mendukung pernyataan word of mouth dapat menjadi penghubung keterkaitan nilai utilitarian dan niat berperilaku (Ryu, et. al, 2010), juga word of mouth dapat membentuk persepsi dan niat berperilaku seorang wisatawan lewat nilainilai yang mereka dapatkan ditempat wisata (Gallarza dan Saura, 2006).

Pelayanan yang diberikan oleh Casa Baio serta manfaat yang mereka dapatkan ketika berwisata ditempat ini sudah sangat mempengaruhi niat para pelanggan untuk kembali mengunjungi tempat ini. Dengan adanya tambahan dari pelaku word of mouth yang menceritakan hal-hal positif lainnya menyangkut pengalaman positif yang mereka dapatkan dari tempat ini, maka para pelanggan dan orang sekitar semakin terdorong untuk datang ditempat ini dan menikmati layanan dan fasilitas yang 
disiapkan pihak resort. Degan demikian, dapat disimpulkan bahwa tanpa word of mouth pun nilai-nilai utilitarian yang ditawarkan Casa Baio Paradise resort akan memberikan pengaruh terhadap niat berperilaku.

\section{Kesimpulan}

Nilai hedonis dan nilai utilitarian dari

Casa Baio Paradise Resort dapat mempengaruhi seorang konsumen untuk melakukan word of mouth postitif mengenai tempat tersebut. Selanjutnya, word of mouth yang disampaikan oleh para pengunjung akan memberikan dampak yang positif terhadap niat berperilaku seorang konsumen. Sehingga konsumen dapat berniat untuk kembali ketempat ini. Nilai utilitarian yang ditawarkan pihak resort juga mampu menciptakan niat berperilaku seorang konsumen untuk kembali berkunjung ketempat ini. Namun, nilai hedonis tidak dapat menciptakan niat berperilaku seorang konsumen untuk kembali berkunjung. Hal ini terjadi karena kurangnya pembaruan yang dilakukan oleh pihak resort terhadap fasilitas resort.

Word of mouth juga didapati memiliki peran mediasi sempurna pada pengaruh nilai hedonis terhadap niat berperilaku. Artinya, NIilai hedonis dapat memberikan pengaruh terhadap niat berperilaku hanya jika melewati word of mouth. Jadi tanpa adanya variabel word of mouth, nilai hedonis tidak akan berpengaruh terhadap niat berperilaku. Sedangkan pada pengaruh nilai utilitarian terhadap niat berperilaku, Word of mouth memiliki peran mediasi sebagian. Artinya, word of mouth dapat menjembatani pengaruh nilai utilitarian terhadap niat berperilaku. Namun tanpa adanya word of mouth, nilai utilitarian mampu memberikan pengaruh terhadap niat berperilaku.

\section{DAFTAR PUSTAKA}

Babin, B. J., Darden, W. R., \& Griffin, M. (1994). Work and/or Fun: Measuring Hedonic and Utilitarian Shopping Value. Journal of Consumer Research, 20(4), 644. https://doi.org/10.1086/209376
Babin, B. J., Lee, Y., Kim, E., \& Griffin, M. (2005). Modeling consumer satisfaction and word-of-mouth: restaurant patronage in Korea. Journal of Services Marketing, 19(3), 133-139. https://doi.org/10.1108/08876040510596 803

Brown, T. J., Barry, T. E., Dacin, P. A., \& Gunst, R. F. (2005). Spreading the Word: Investigating Antecedents of Consumers' Positive Word-of-Mouth Intentions and Behaviors in a Retailing Context. Journal of the Academy of Marketing Science, 33(2), 123-138. https://doi.org/10.1177/00920703042684 17

Carpenter, J. M., \& Fairhurst, A. (2005). Consumer shopping value, satisfaction, and loyalty for retail apparel brands. Journal of Fashion Marketing and Management: An International Journal, 9(3), 256-269. https://doi.org/10.1108/13612020510610 408

Chen, C.-F., \& Tsai, D. (2007). How destination image and evaluative factors affect behavioral intentions? Tourism Management, 28(4), 1115-1122. https://doi.org/10.1016/j.tourman.2006.0 7.007

Chevalier, J. A., \& Mayzlin, D. (2006). The Effect of Word of mouth on Sales: Online Book Reviews. Journal of Marketing Research, 43(3), 345-354. https://doi.org/10.1509/jmkr.43.3.345

Chiu, C.-M., Wang, E. T. G., Fang, Y.-H., \& Huang, H.-Y. (2014). Understanding customers' repeat purchase intentions in B2C e-commerce: the roles of utilitarian value, hedonic value and perceived risk. Information Systems Journal, 24(1), 85114. https://doi.org/10.1111/j.13652575.2012.00407.x

Gallarza, M. G., \& Gil Saura, I. (2006). Value dimensions, perceived value, satisfaction and loyalty: an investigation of university students' travel behaviour. 
Tourism Management, 27(3), 437-452. https://doi.org/10.1016/j.tourman.2004.1 2.002

Ha, J., \& (Shawn) Jang, S. (2010). Perceived values, satisfaction, and behavioral intentions: The role of familiarity in Korean restaurants. International Journal of Hospitality Management, 29(1), 2-13. https

Han, H., \& Kim, W. (2009). Outcomes of relational benefits: restaurant customers' perspective. Journal of Travel \& Tourism Marketing, 26(8), 820-835. https://doi.org/10.1080/10548400903356 236

Hartline, M. D., \& Jones, K. C. (1996). Employee performance cues in a hotel service environment: Influence on perceived service quality, value, and word-of-mouth intentions. Journal of Business Research, 35(3), 207-215. https://doi.org/10.1016/01482963(95)00126-3

Holbrook, M. B., \& Hirschman, E. C. (1982). The Experiential Aspects of Consumption: Consumer Fantasies, Feelings, and Fun. Journal of Consumer Research, $9(2)$, 132. https://doi.org/10.1086/208906

Hyun, S. S., Kim, W., \& Lee, M. J. (2011). The impact of advertising on patrons' emotional responses, perceived value, and behavioral intentions in the chain restaurant industry: The moderating role of advertising-induced arousal. International Journal of Hospitality Management, 30(3), 689-700. https://doi.org/10.1016/j.ijhm.2010.10.00 8

Jalilvand, M. R., Esfahani, S. S., \& Samiei, N. (2011). Electronic word-of-mouth: Challenges and opportunities. In Procedia Computer Science (Vol. 3, pp. 42-46). https://doi.org/10.1016/j.procs.2010.12.0 08 perkembangannya di Indonesia. Gramedia Widiasarana Indonesia untuk Lembaga Studi Pariwisata Indonesia.

Ladhari, R. (2009). Service quality, emotional satisfaction, and behavioural intentions. Managing Service Quality: An International Journal, 19(3), 308-331. https://doi.org/10.1108/09604520910955 320

Maio, G. R., \& Olson, J. M. (1995). Relations between Values, Attitudes, and Behavioral Intentions: The Moderating Role of Attitude Function. Journal of Experimental Social Psychology, 31(3), 266-285. https://doi.org/10.1006/jesp.1995.1013

Molinari, L. K., Abratt, R., \& Dion, P. (2008). Satisfaction, quality and value and effects on repurchase and positive word-of-mouth behavioral intentions in a B2B services context. Journal of Services Marketing, 22(5), 363-373. https://doi.org/10.1108/08876040810889 139

Nejati, M., \& Parakhodi Moghaddam, P. (2012). Gender differences in hedonic values, utilitarian values and behavioural intentions of young consumers: insights from Iran. Young Consumers, 13(4), 337-344.

https://doi.org/10.1108/17473611211282 581

Nejati, M., \& Parakhodi Moghaddam, P. (2013). The effect of hedonic and utilitarian values on satisfaction and behavioural intentions for dining in fastcasual restaurants in Iran. British Food Journal, 115(11), 1583-1596. https://doi.org/10.1108/BFJ-10-20110257

O’Curry, S., \& Strahilevitz, M. (2001). Probability and Mode of Acquisition Effects on Choices Between Hedonic and Utilitarian Options. Marketing Letters, 12(1), 37-49. https://doi.org/10.1023/A:100811590290 4 
Oliver, R. L. (1997). Satisfaction: a behavioral perspective on the consumer. McGraw Hill.

Overby, J. W., \& Lee, E.-J. (2006). The effects of utilitarian and hedonic online shopping value on consumer preference and intentions. Journal of Business Research, 59(10-11), 1160-1166. https://doi.org/10.1016/j.jbusres.2006.03. 008

Park, H., \& Sullivan, P. (2009). Market segmentation with respect to university students' clothing benefits sought. International Journal of Retail \& Distribution Management, 37(2), 182201. https://doi.org/10.1108/09590550910934 308

Ryu, K., Han, H., \& Jang, S. (Shawn). (2010). Relationships among hedonic and utilitarian values, satisfaction and behavioral intentions in the fast-casual restaurant industry. International Journal of Contemporary Hospitality Management, 22(3), 416-432. https://doi.org/10.1108/09596111011035 981

Sen, S., \& Lerman, D. (2007). Why are you telling me this? An examination into negative consumer reviews on the Web. Journal of Interactive Marketing, 21(4), 76-94. https://doi.org/10.1002/dir.20090

Söderlund, M., \& Rosengren, S. (2007). Receiving word-of-mouth from the service customer: An emotion-based effectiveness assessment. Journal of Retailing and Consumer Services, 14(2), 123-136.

https://doi.org/10.1016/j.jretconser.2006. 10.001

T.K. Luk, S., Sharma, P., \& S.N. Chen, I. (2013). Shopping motivation as a moderator in the retail service evaluation. Journal of Services Marketing, 27(1), 40-48. https://doi.org/10.1108/08876041311296 365
To, P.-L., Liao, C., \& Lin, T.-H. (2007). Shopping motivations on Internet: A study based on utilitarian and hedonic value. Technovation, 27(12), 774-787. https://doi.org/10.1016/j.technovation.20 07.01.001

UNWTO Tourism Highlights. (2015). Tourism.

https://doi.org/10.18111/9789284416899

Xia, L., \& Bechwati, N. N. (2008). Word of Mouse. Journal of Interactive Advertising, $\quad$ 9(1), 3-13. https://doi.org/10.1080/15252019.2008.1 0722143

Zeithaml, V. A., Berry, L. L., \& Parasuraman, A. (1996). The Behavioral Consequences of Service Quality. Journal of Marketing, 60(2), 31. https://doi.org/10.2307/1251929 